\title{
Outer approximation algorithms to solve semi- infinite environmental pollution problems
}

\section{Algoritmos de aproximaciones externas para resolver problemas semi-infinitos de contaminación ambiental}

\author{
DOI: http://dx.doi.org/10.17981/ingecuc.14.1.2018.02
}

Research Article. Submission Date: 05/10/2017. Accepted: 24/01/2018.

\author{
Alina Fedossova \\ Universidad Nacional de Colombia. Bogotá (Colombia). \\ afedosova@unal.edu.co \\ Valery Fedosov \\ Independent Researcher. Moscow (Russia). \\ vlr.fdsv@gmail.com \\ Oscar Yecid Buitrago Suescún \\ Universidad Militar Nueva Granada. Bogotá (Colombia). \\ oscar.buitrago@unimilitar.edu.co
}

To cite this article:

A. Fedossova, V. Fedosov y O.Buitrago. "Outer approximation algorithms to solve semi-infinite environment pollution problems" INGE CUC, vol. 14, no. 1, pp. 19-29, 2018 DOI: http://doi.org/10.17981/ingecuc.14.1.2018.02

\begin{abstract}
Introduction- The traditional approaches of managing the integral estimation of a general function do no solve the problem of fulfilling the constraints in each point of the domain. This is achieved through a semi-infinite formulation of the problem, in which there are great possibilities in modeling many practical situations of industrial ecology. Some of them are presented in this paper.

Objective- Based on detailed studies ([1]-[3]), the aim of this research paper is to examine the mentioned studies in order to contribute to disseminate SIP (Semi-Infinite Programming) applications in environmental pollution control.
\end{abstract}

Methodology- With regard to the numerical solution a stochastic outer approximation algorithm was used, in addition numerical experiments were performed in MATLAB.

Results- The obtained results of this work have showed three patterns, the first one enhances the power of emitting pollution sources, taking into account the area landscape, the second one also enhances the power of pollution sources using wind displacement of emissions, finally the third pattern operates by improving the pollution of $3 \mathrm{D}$ areas between a group of emission sources and purifiers.

Conclusions- In conclusion, it can be said that the issue of power from emitting pollution sources, by considering the area landscape and wind displacement of emissions, should be modeled such as a semi-infinite programming trouble. The method used to calculate the algorithm stopping criterion, does not interpret this solution as an additional problem.

Keywords-Semi-infinite programming, stochastic programming, pollution, outer approximation algorithms, contamination standards.

\section{Resumen}

Introducción- Los enfoques tradicionales de gestión de la estimación integral de una función general no resuelven el problema de cumplir con las restricciones en cada punto del dominio. Esto se logra mediante una formulación semi-infinita del problema, en la que existen grandes posibilidades para modelar muchas situaciones prácticas de la ecología industrial. Algunos de ellos se presentan en este documento.

Objetivo- Basándose en estudios detallados ([1]-[3]) el propósito de este artículo es examinarlos y contribuir a difundir las aplicaciones de la programación semi-infinita (SIP) en la solución de problemas de control de contaminación ambiental. Metodología- Para su solución numérica se aplica el algoritmo estocástico de aproximaciones externas. Los experimentos se realizan en MATLAB.

Resultados- Se presentan tres modelos, uno de ellos optimiza la potencia de emisiones de contaminación por fuentes de contaminación teniendo en cuenta el área de ambiente. Segundo, optimiza la potencia de fuentes de polución con sus desplazamientos causado por el viento y el último optimiza la polución en áreas 3D entre un grupo de contaminantes y un grupo de purificadores.

Conclusiones- El problema de optimización de emisiones de las fuentes de contaminación teniendo en cuenta el área y sus desplazamientos por causa del viento puede ser modelado y resuelto como un problema de optimización semi-infinita. El criterio de parada del método utilizado no requiere solución de un problema adicional como normalmente sucede en este tipo de programación.

Palabras clave- Programación semi-infinita, programación estocástica, polución, algoritmos de aproximaciones externas, normas de contaminación. 


\section{INTRODUCTION}

The traditional approaches which cope with the integral estimation of a general function do not solve the problem of fulfilling the constraints of the above mentioned issue in each point of the domain, in this case a goal was achieved by a semi-infinite formulation of the problem, in which there exist considerable possibilities in modeling several practical situations of industrial ecology. A selected group of them are presented in this paper.

SIP problems $(P(Y))$ are part of non-classical improvement, they consist essentially in determining a vector $X$ by minimizing the objective function with constraints: $\min \mathrm{f}(\mathrm{x})$ s.t $\mathrm{g}(\mathrm{x}, \mathrm{y}) \leq 0, \mathrm{y} \in \mathrm{Y}$.

If $X$ and $Y$ are finite, this is a common problem of mathematical programming, therefore, there exist difficulties in which the number of $X$ variables is finite, as well the number related to $Y$ constraints is also infinite, for instance, in case of $Y$ matches to the spatial coordinates [4]-[6]. Typically the area of pollution control describes an infinite number of points, so the assignment of tasks to optimize industrial ecology becomes semi-infinite.

A number of algorithms for SIP problems reduce the semi-infinite problem to a finite one and solve it by classical methods of linear or nonlinear programming. Typically, each of the constraints or the objective function are nonlinear, so that the problem often involves nonlinear programming [7].

The stochastic outer approximations method, used in this work, applies active and passive research techniques of active constraints. The semi-infinite optimization task was change into a series of tasks of finite optimization, each of these has a single active constraints in a given iteration, this algorithm was applying in an appropriate way previously intended for robotics issues. On the other hand Chebyshev approximation difficulties, air pollution and others features were based on the optimal criteria of quasioptimal functions.

The general problem was founded on the minimization of pollution control for an area where pollution sources are produced, the first one attempted to solve the problem of air pollution ( $2 \mathrm{D}$ case) by using a

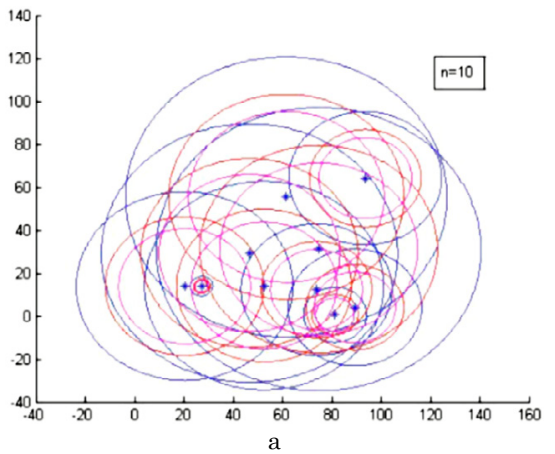

stochastic outer approximations algorithm which was building appropriately in the present paper [6], [8]:

$$
\begin{aligned}
& \min _{\mathrm{x} \in \mathrm{R}^{n}} c_{j} x_{j} \\
& g(x, s)=\sum_{j=1}^{n}\left(1-x_{j}\right) u_{j}(\mathrm{~s}) \leq \varphi(\mathrm{s}) \quad \forall \mathrm{s} \in \mathrm{S},
\end{aligned}
$$

where $x_{1}, \ldots, x_{n}[0,1]$ are reductions factor of pollution, $u_{j}, \mathrm{j}=1, \ldots, \mathrm{n}$ are functions of pollution distribution, $c_{j}, \mathrm{j}=1, \ldots, \mathrm{n}$ are cost of purification, is function of norm, $S$ is explained as a control area and $n$ is a number of pollution sources.

As a result of applying optimization ([8]), the solution $(0,0,0.27)$ was received at the beginning of the examination from the point $(0,0,0)$, which indicates as individual the third plant which has been reduced about $27 \%$ of the pollution emission.

The choice of the main variables is a command from the specific need to find the percentage values of the reduction of pollution in order to fulfill the current standards specified by the function $\varphi$. Due to functions $u_{j}$, a mathematical pattern receives data on the current distribution of pollution and its form. By modifying the vector $\mathrm{c}$, it should be possible by taking into account the costs of a hypothetical purification after optimization.

Now, finiteness of the number of emission sources in practice not only simplifies the hinder but also in the basic $t$ representation is evident the speed of the situation concerning to polluting the territory and its complications related to a marginal increase in the number of emission sources. Fig. 1 shows the superposition of spherical zones of pollution spread for 3 component sources with a randomly selected power and randomly distributed on the conditional ground of [100x70] units, on the other hand, asterisks indicate the coordinates of sources. In case of sources number 10 (fig. 1a) these allowed the researches to trace the place theoretically with severe contamination, through 50 sources overlay zones that are already compacted, and at 100 (fig. 1b) in other words, every part is fused into a spot and the whole visual analysis attempts are unmanageable. In this study the question under discussion is the type and potential analysis of such contamination function.

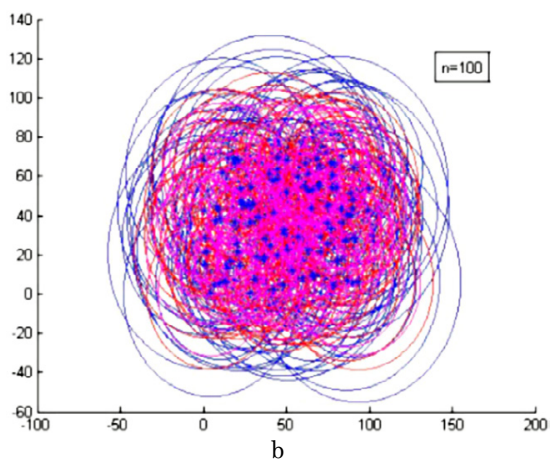

Fig. 1. Superposition of spherical zones of pollution spread by component, for 10 sources in a, and 100 sources in b. Source: Authors. 
This paper illustrates three mathematical prototypes of environmental pollution difficulties and the application of stochastic outer approximating method to solve the mentioned difficulties. Turning to patterns, it is significant to mention that the first one enhances the power of emitting pollution sources, taking into account the area landscape, the second one also enhances the power of pollution sources using wind displacement of emissions, finally the third one operates by improving the pollution of $3 \mathrm{D}$ areas between a group of emission sources and purifiers.

The proposed algorithm should solve semi-infinite programming difficulties, including the case that refers to a number of sources in the solution that increases significantly or which is regarded as virtual.

The basic structures to set SIP problems lies in the construction of the restrictions according to these algorithms, during the first stage stochastic procedures within the announced limit of attempts it is able to find the point of failure of constrains. During the second stage the limit is viewed as a function of the territory coordinates and carries out its maximization from the start point of the first stage so that it takes advances by allowing the identification as well as the coordination of the nearest LMF (local maximum failure of constraints). During the third stage, there is a possibility to find a new LMF which also interrupts the constraints, hence its parameters are used to calculate the line of optimization in a matrix. in that case the solution is related to the vector and its change of power from $X$ source, hence to accomplish the algorithm some alternatives should be suggested such as a pause in the variation of the objective function, the lack of new points of failure of constrains within the limit of attempts, or a stabilization of $X$ otherwise, the advantage of a stochastic procedure is the identification of a LMF map that contains some segment of calculated territory points which do not exceed 3-4\%, so it describes that the preliminary point of failure of constrains is frequently established in the study area $d$. On the contrary, the coordinates of detected LMFs should be located in $\mathrm{d}$ and outside $d$.

The number of LMFs and their coordinates do not necessarily match with the number and coordinates of emission sources; algorithms with different starting points of failure of constrains are able to detect duplicated LMFs, since repeated LMFs screenings take place, the number of rows of the optimization matrix will be relatively minor.

\section{Methodology}

The stochastic outer approximating method was used in this research work to solve the $\mathrm{P}(\mathrm{Y})$ difficulties [8], [9]. This approach can be considered as a developed Eaves-Zangwill, a method which applying the multistart technique in whole of the iterations for the research of relevant constraints parameters.
The above mentioned technique consists in replacing the original problem $P(Y)$ with a sequence of approximating problems $P\left(Y_{\mathrm{n}}\right)(2), n=1,2, \ldots$, where every problem $P\left(Y_{\mathrm{n}}\right)$ depends entirely on the finite set of parameters $Y_{\mathrm{n}}$ :

$$
\begin{array}{ll}
P(Y n) & f(x) \rightarrow \min \\
g(x, y) \leq 0, & \mathrm{y} \in Y_{n}
\end{array}
$$

The applied algorithm is a version of the general SMETH.ACTIV algorithms, proposed by Zavriev and Volkov by [9] including a explicit quasi-optimality function (optimal criterion) (3):

$$
\begin{aligned}
& \Theta(x, Y)=\max \left(f(x)-\min _{x \in X:} f(x), \max _{y^{\prime} \in Y} g\left(x, y^{\prime}\right)\right) \\
& g(x,) \leq 0 \quad \forall y \in Y
\end{aligned}
$$

Turning to Industrial ecology problems, these typically identify the indicator of emission sources and regulatory constraints for such emissions for objects (zones), correspond in the same way to this formulation [1]. Tasks are built on the basis of their conflict constrains. Both groups of participants have the exact coordinate attachment within the allocated ground. Outer approximation algorithms discover a variety of failures of constrains as well the critical ones for the whole area and determine this redundancy for each emission source.

The whole programming was conducted in MAT$\mathrm{LAB}$, as this system is focused on matrix operations, it contains predetermined functions of stochastic selection, maximized parameters on several variables of linear and nonlinear programming as well powerful and dynamic graphics, in addition to describe the emission sources, monitoring data or forecasts should be used, nevertheless mathematical functional such as Gauss, parabolic and others were additionally applied. With regard to functions, the parabolic ones were used in this work, due to their adaptation and compatibility so all of their variables match to the basic spread parameters which include settled complications.

The quantity of pollution from $j$ source for $k$ component at s point on area (region) with parabolic dispersion is $h(j, k, s)=-a(k) r(j, s)^{2}+H(j)$, where $H(j)$ illustrates the discharge power of $j$ source (during the period); $a(k)$ meanwhile the coefficient of dispersion parabola for $k$ component of pollution; $r(j$, $s$ ) demonstrate the distance of $j$ source from $s$ point.

The amount of the emission sources determines the total pollution points on a territory, assumed that the total pollution is a function that will be characterized by two features: 1) despite of the differentiability of the functions of individual emission sources, the function of the overall pollution, due to an arbitrary location of sources in some places of the territory, it should become non-differentiable and even have discontinuities; 2) imposition of unimodal functions of individual emission sources, leading a kind of multiple purpose worldwide pollution rule. 
The stochastic outer approximations method is supplemented by elements of the stochastic research which allows the algorithm to work applying these functions. SIP allows entering the parametric chart of the territory (2D) or the area (3D) into the model by observing the results on $2 \mathrm{D}$-3D screen graphics.

Beside of the sources of emissions, the ground (region) is characterized by pollution regulation of objects (zones). These can be described by a single constant scalar, in case of breaking apart into objects (zones) - by multi-level regulations (vector); in contrast this should be possible through a specific analytic function.

\section{III.RESULTS}

The results of the present work found clear support of a number of statements related to industrial ecology issues (description of constraints, some initial data, numerical and graphical results) obtained from the basis of problem (1) by solving them using versions of stochastic outer approximations algorithms

\section{A. Enhancing control of pollution emissions sources taking into account the landscape area}

Despite the efforts to reduce the impact of industry on the environment, there exist several habitats where pollution concentration exceeds the critical standard and present a singular balanced with regard to the surrounding landscape, furthermore the situation of the territories are entirely factual where social, environmental and industrial zones do not only coexist, but are often combined.

The following pattern displays several areas of infrastructure which included: 1) buildings (settlements, trade, cultural and similar structures) 2) water areas (sea, rivers, inland waters); 3) green areas (forests, parks); 4) free areas; 5) mountains.

On the area chart should be a number of regulatory zones as needed, with arbitrary boundaries. Multicomponent emissions composition, in the form of a variable set of $\mathrm{K}$ components, was considered.

To determine the vector of emissions excess of each group of industrial emissions sources, located on the same assets as regulatory objects (zones) as a rule the restrictions of the problem take the following form (4): where $x(j)$ lists the reduction in the intensity of pollution emission of source $j(0 \leq x(j) \leq 1), q(k, j)$ as a result it refers to the code which determines the $\mathrm{k}$-th emission component presence in source $j,(s, k, v)$ it shows the level of initial pollution at point $s$ with the k-th component with the zone type $v ; \varphi(s, k, \omega)$ that is an acceptable rate for the $\mathrm{k}$-th component pollution at $\mathrm{s}$ point with the accounted type of zone $\omega$.

The parabolic type (5) was selected for the objective function:

$\min f(x)=\Pi \sum_{j=1}^{n} \sum_{k=1}^{K} q(k, j) x(j)(2-x(j)) H^{2}(j) \frac{m(k)}{2 a(k)}$

Where $m(k)$ is the unpolluted value for the component $k, H(j, t)$ - the emission intensity by source $j$ at point $s$ during the period.

Table 1 shows raw data of a numerical experiment (conventional units): $N=15$ (the number of sources), $d[600,300]$ (area size), where $H$ illustrates the power vector and $t$ is the source coordinates matrix. The vector of parabola constants of pollution components dispersion was $a=\left(12 \cdot 10^{-4} \ldots 21 \cdot 10^{-3}\right)$. Functions $(s, k, v)$ and $\varphi(s, k, \omega)$ are represented by digitized charts also the $q$ Matrix does not provide a specific explanation.

The mentioned algorithm starts from zero values of the solution vector, the point of departure from single values of the solution vector does not start with algorithms, since all constrains are satisfied and deduced. In the same way LMF can be found by maximizing different points of failure of constrains, the number of rows in the solution matrix should be the maximum, so the deviation of overlapping rows of the matrix should be provided.

While new LMFs are found, the probability of discovering of the remaining ones changes. The compensation is estimated by an increase of random points limit during every subsequent iteration. The algorithm should discard the industrial zones adjacent to the sources of emissions, since they have their own safety standards.

Line 6 of Table 1 shows the vector of optimal solution of the problem, and line 7 shows the optimal vector of power sources. The pattern has previously defined parameters rather than solid optimization results, the complete withdrawal of five companies of the ground is required due to them were completely appropriate for pollution standards, the remaining ones regulate their power as a requirement.

$$
\begin{aligned}
g(x, s) & =\sum_{\substack{<=1 \\
j=1}}^{n} q(1, j)(1-x(j))\left(-a(k) \mathrm{r}(s, j)^{2}+\mathrm{H}(j)\right)+\lambda(s, 1, v)-\varphi(s, 1, \omega) \\
& \ldots \\
g(K) & =\sum_{j=1}^{n} q(K, j)(1-x(j))\left(-a(k) \mathrm{r}(s, j)^{2}+\mathrm{H}(j)\right)+\lambda(s, K, v)-\varphi(s, K, \omega) \leq 0
\end{aligned}
$$


TABLE 1. INITIAL EXPERIMENTAL DATA.

\begin{tabular}{|c|c|c|c|c|c|c|c|c|c|c|c|c|c|c|c|}
\hline \multirow{2}{*}{ Parameters } & \multicolumn{15}{|c|}{ Sources numbers } \\
\hline & 1 & 2 & 3 & 4 & 5 & 6 & 7 & 8 & 9 & 10 & 11 & 12 & 13 & 14 & 15 \\
\hline $\mathrm{H}$ & 157 & 175 & 58 & 29 & 154 & 190 & 150 & 124 & 140 & 166 & 98 & 27 & 118 & 73 & 81 \\
\hline \multirow{2}{*}{$t$} & 575 & 130 & 315 & 210 & 395 & 570 & 19 & 339 & 81 & 80 & 347 & 504 & 451 & 533 & 478 \\
\hline & 29 & 213 & 247 & 242 & 282 & 148 & 25 & 276 & 241 & 108 & 242 & 263 & 191 & 211 & 135 \\
\hline $\mathrm{x}$ & 0.12 & 0.62 & 1 & 1 & 0.39 & 0.30 & 0 & 0 & 0 & 1 & 0,47 & 0 & 0 & 1 & 1 \\
\hline$(1-x) H$ & 138 & 67 & 0 & 0 & 95 & 133 & 150 & 124 & 140 & 0 & 52 & 27 & 118 & 0 & 0 \\
\hline
\end{tabular}

Source: Authors.
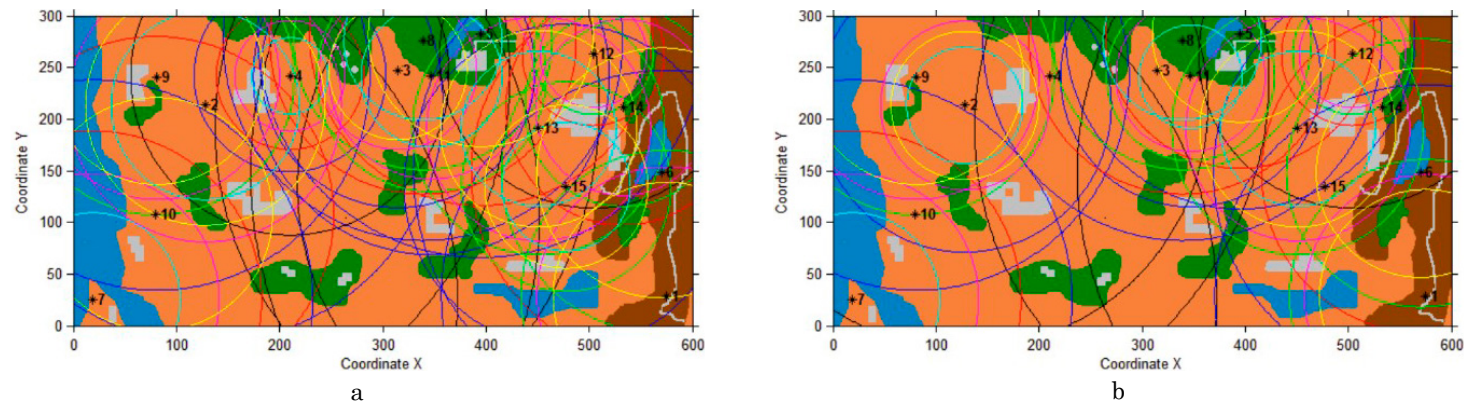

Fig. 2. Dispersion zone of the active contamination components by sources, before (a) and after (b) optimization. Source: Authors.
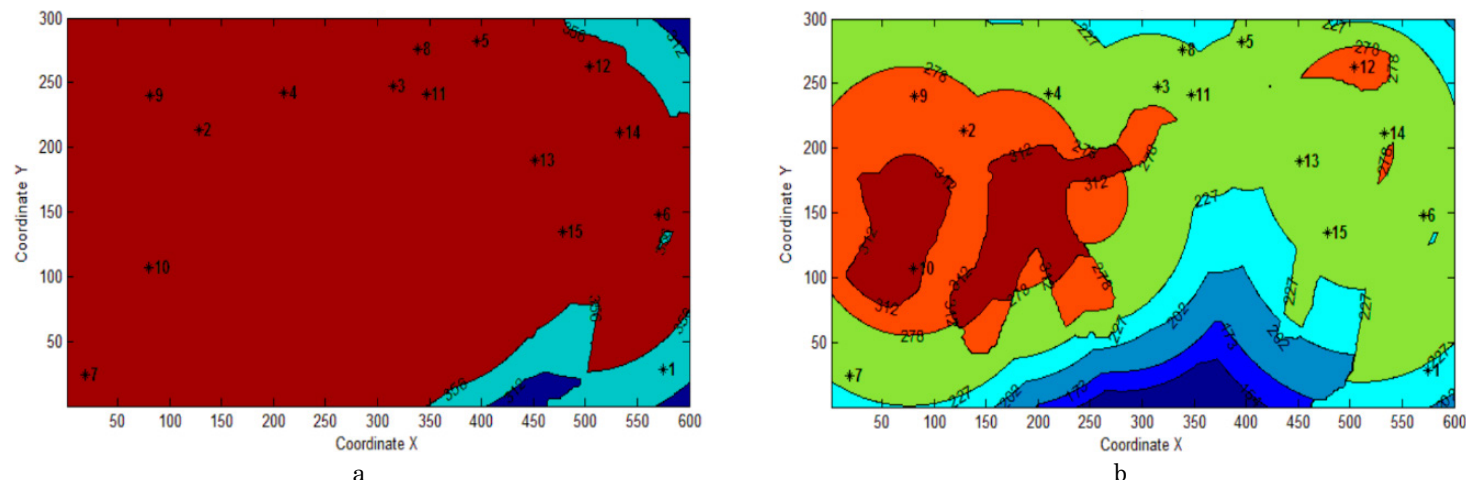

Fig. 3. Maps of contamination by component 1 (a - initial, b - after optimization). Source: Authors.

Fig. 2 shows a chart of the regulatory locations (areas) and the circumferences of spread from the active pollution components by sources before (a) and after (b) optimization. However, only a general weakening of the polluting load in the area is perceived. The outer approximations algorithm allow showing the comparative graphs of optimal solutions.

Fig. 3 shows the chart from the original (a) and optimal (b) pollution for component 1 . If it was supported on the source of pollution and its relevance $(\geq$ 356 conventional units), it captured almost the whole ground as well its compliance with pollution standards was unknown, the optimization would have left only a few local spots of contamination of that level and it would have made it possible for the regulatory traces (zones) to function. Component 7 (Fig. 4) it includes a significant improvement of its ecology mainly in the northwest and southeast of the area.
Also, the scope of absolutely unpolluted zone was increased. As for the current objects appeared, the area of their chosen settlement was visible, thus according to component 1 it is not appropriate to place such objects near sources 10,12; often sources of emissions, initially are suggested as marginal, with regard to the expansion of the ground which promptly become internal so the unfavorable influence of the last is advanced, by following that simulation it allows restricting emissions to full egression of sources with critical power or disadvantageous position which is especially significant for large developing cities, for that purpose several years have been spent to build facilities on areas so it is not common these one should have been developed from central locations being the outcome of a number of managers, so the introduction of compliance standards is not only a matter of time but also the best option. 

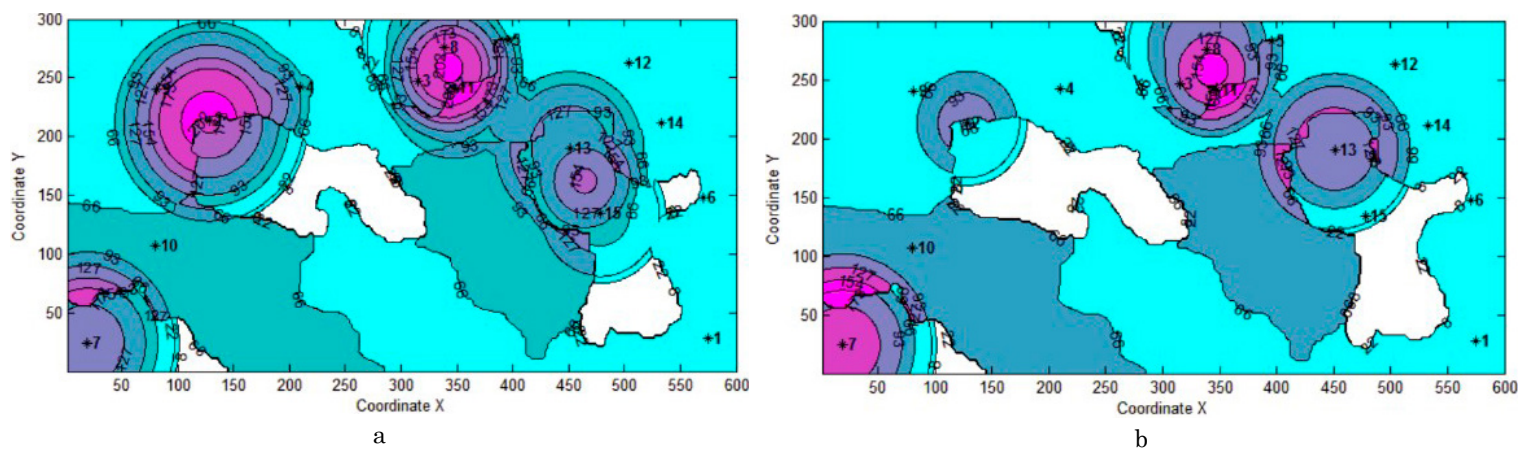

Fig. 4. Maps of contamination by component 7 (a- initial, b- after optimization). Source: Authors.

Periodic optimization of pollutant loads should go along with the development of local infrastructure.

\section{B. Optimization of power of pollution sources with wind displacement of emissions}

When modeling pollution control through significant distortions arise from the wind displacement this turns into a close compulsory weather factor that can both weaken or strengthen general and local areas of pollution, at the same time a part of the pollutants should leave the controlled area, on the other hand, an infiltration of the contamination trail from the bordering regions can take place due to the effect of the wind (cross-border transfer).

SIP allows including the wind displacement directly into the algorithm of optimization of emission sources (taking them into account at each iteration), which makes the solution accurate after that the existence of wind generates new multi-extremely spread functions, the mentioned

Functions parameters whereas wind are defined by direction and intensity. On the assumption of wind direction is given quite simply its intensity is conceived as complicated to determine. The present work proposes to replace $\mathrm{n}$ of the original sources operating on the territory by n-series of virtual sources (6) with a total capacity of emissions equivalent to the original, illustrated by the following image

$$
P(j)=\sum_{i=1}^{w} p(i, j)
$$

where: $P(j)$ is the integrated power of the $\mathrm{j}$-th power source $(j=1 \ldots n) ; p(i, j)$ is integral emissions of the $\mathrm{i}$-th virtual source $(i=1 \ldots w)$ in the $j$ series, after all integral emissions in a series of virtual sources are not necessarily equivalent between them in other words, it depends on the nature of the wind. Researchers of this work will consider decreasing distribution corresponding to a weak wind (har $=1$ ), even to a moderate one (har $=2)$, and increasing to a strong one (har $=3)(7)$

$$
P(i, j)=\left\{\begin{array}{c}
P(j)(\omega+1-i), \text { если har }=1 \\
\frac{P(j)}{w}, \text { если } h a r=2 \\
P(j) \frac{i}{d e l i}, \text { если } h a r=3
\end{array}\right.
$$

where deli $=1+2+\ldots+w$.

Replacing scalar $\mathrm{u}($.$) by \mathrm{u}$ vector allowed researchers to examine autonomous wind directions from each of the original sources as well the whole pattern of the ground can be quite complex which ones are conventionally illustrated by charts of wind streamlines.

On Fig. 5, the possible streamlines for the ground and their positions are displayed, by coding values to vector $\mathrm{u}$ in accordance with the location coordinates of the pollution sources it includes wind function into the algorithm, therefore the following features were interpreted: 1) the vector of directions for sources in accordance with streamline patterns; 2) the nature of the distribution of virtual power sources in the series; 3) similar 1 sets of pollution components of initial sources and corresponding series of the virtual ones; 4) power and coordinates of the virtual sources in the series; 5) charts of initial exploded pollution of the area; 6 ) charts of trans boundary transport of pollution components.

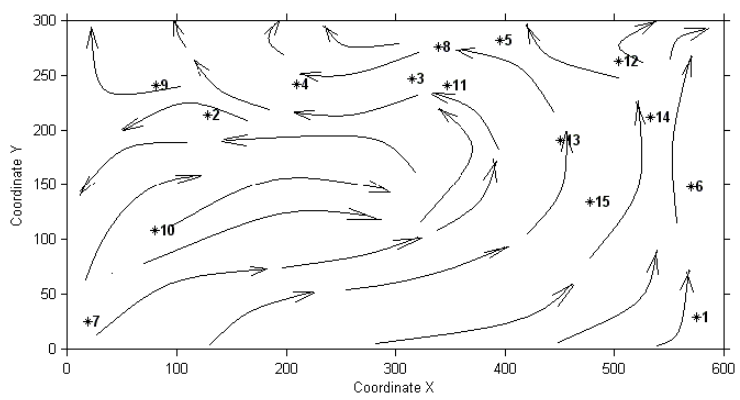

Fig. 5. Map of the streamlines of the wind in the experiment. Source: Authors.

Objective function (8) with expenditure sense to provide the optimization in $\mathrm{n} \times \mathrm{w}$ virtual sources: 


$$
\min f(x)=\Pi \sum_{k=1}^{K} \sum_{m=1}^{n w} q(k, m) x(m)(2-x(m)) H^{2}(j) \frac{z(k)}{2 a(k)}
$$

Constraints (9) are generated on the basis of virtual sources' emissions and other emissions:

$$
\begin{aligned}
g(k)= & \sum_{j=1}^{n} q(k, j) \sum_{i=1}^{w}(1-x(i, j)) h(s, k, t, u, i, j) \\
& +\lambda(s, k, v)+\gamma(s, k)-\varphi(\omega(s), k) \leq 0
\end{aligned}
$$

Here: $g(k)$ is the $\mathrm{k}$-th limitation of the model; $q(k$, $j)$ is the code of the presence in the $\mathrm{j}$-th series of $\mathrm{k}$ th emission component; $x(i, j)$ is the reduction of the intensity of pollution emissions by the i-th source in the $\mathrm{j}$-th series; $h(s, k, t, u, i, j)$ is the intensity of the emission at point $\mathrm{s}$ of the $\mathrm{k}$-th component by the $\mathrm{i}$-th virtual source in the $\mathrm{j}$-th series with $t$ coordinates and $u$ beam angle; $\lambda(s, k, v)$ is the function of the initial area of pollution at s point by k-th component for $v$ zone; $(s, k)$ is the function of the initial cross-border transfer of the k-th pollution component; $\varphi(\omega(s)$, $k$ ) is the function of the allowed rate for the $\mathrm{k}$-th contamination component taking into consideration $\omega(s)$ landscape zones. $K$ is the number of pollution components $k=1 \ldots K$.

The available evidence seems to suggest that during the research, the number, capacity and location of the emission sources are in accordance with Table 1, and local directions as well the nature of wind displacements of sources are given in Table 2 , it appears probable that the introduction of virtual sources, simulating wind displacements has changed the map of zones of pollution components are scattered by initial power of emission sources (Fig. 6a) accordingly wind caused significant transboundary pollution redistribution, essentially in the north-east direction as a consequence the polluted territory has increased.

The algorithm changed the length of the optimal solutions vector from 15 to 75 (because of its length it is not given) and suggested an appropriate chart of pollution which has been spread (Fig. 6b), here the concentration in spread zones has declined, even though the direction of cross-border trail was maintained.

In addition the decision allowed the pollution mapping on the extended territory but emission components. Fig. 7a shows the original trail of pollution for Component 3, a specific group of fifteen sources contain element 3 in the emissions (specifically 4 - 8, 10,12 and 14 admite it) A ridge of pollution in the northeast direction is embodied on the fragment [300 $x$ 600] under the influence of strong emissions by sources $7(\mathrm{H}=149)$ and $10(\mathrm{H}=165)$. Further, it is also supported by the emissions of significant power by sources 5 (154) and 8 (123) in a similar direction. However, due to the boundary location, their total emissions are previously deserting the original territory. With reference to sources $12(\mathrm{H}=26)$ and 14 $(\mathrm{H}=72)$ these are influenced by wind in different courses especially the northwestern, however their power is even now considerably minor. As a result, the calculation of the impact on the expanded territory [700 x 900] where a trail was built with a pro-

TABLE 2. INITIAL EXPERIMENTAL DATA.

\begin{tabular}{|c|c|c|c|c|c|c|c|c|c|c|c|c|c|c|c|}
\hline \multirow{2}{*}{ Parameters } & \multicolumn{10}{|c|}{ Sources numbers } \\
\cline { 2 - 39 } & 1 & 2 & 3 & 4 & 5 & 6 & 7 & 8 & 9 & 10 & 11 & 12 & 13 & 14 & 15 \\
\hline $\mathrm{u}, \mathrm{rad}$ & 2.4 & 1 & 0.8 & 0.9 & 1.1 & 1.6 & 0.6 & 0.8 & 1.3 & 0.85 & 0.95 & 2.1 & 1.8 & 1.9 & 1.6 \\
\hline har & 3 & 1 & 1 & 3 & 3 & 1 & 1 & 1 & 3 & 1 & 2 & 3 & 1 & 2 & 2 \\
\hline
\end{tabular}

Source: Authors.
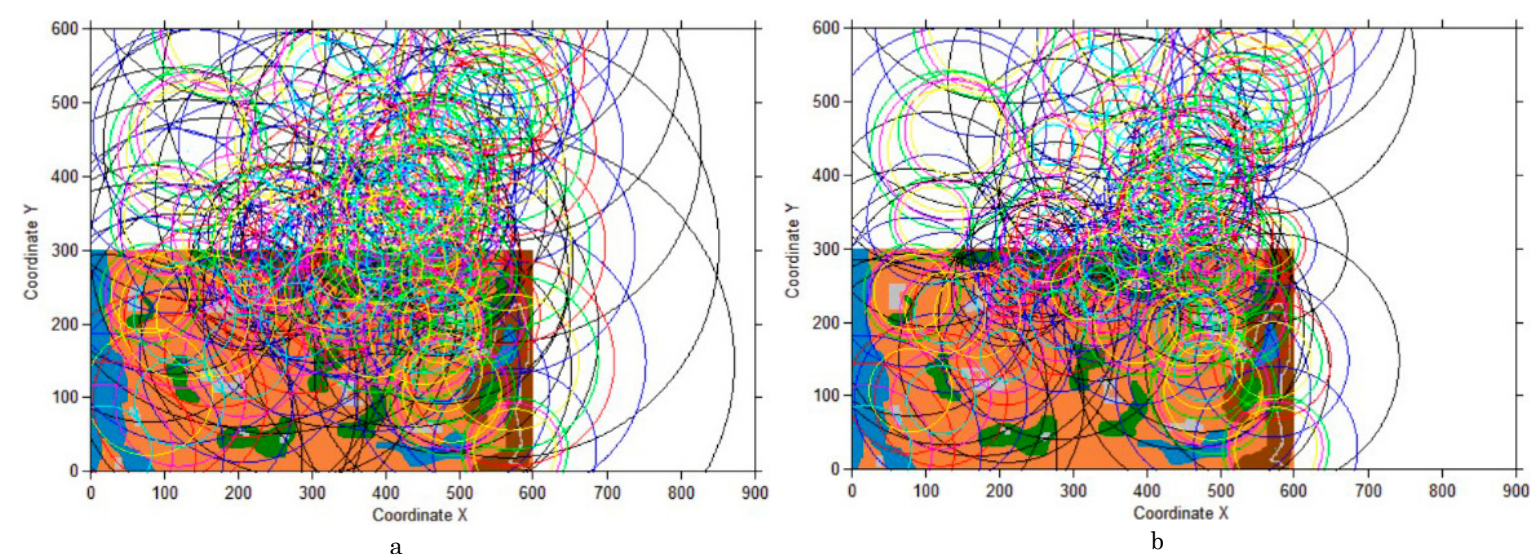

Fig. 6. Maps of contamination spread on the area by components 1-7 with wind displacements (a- initial, b- after optimization). Source: Authors. 

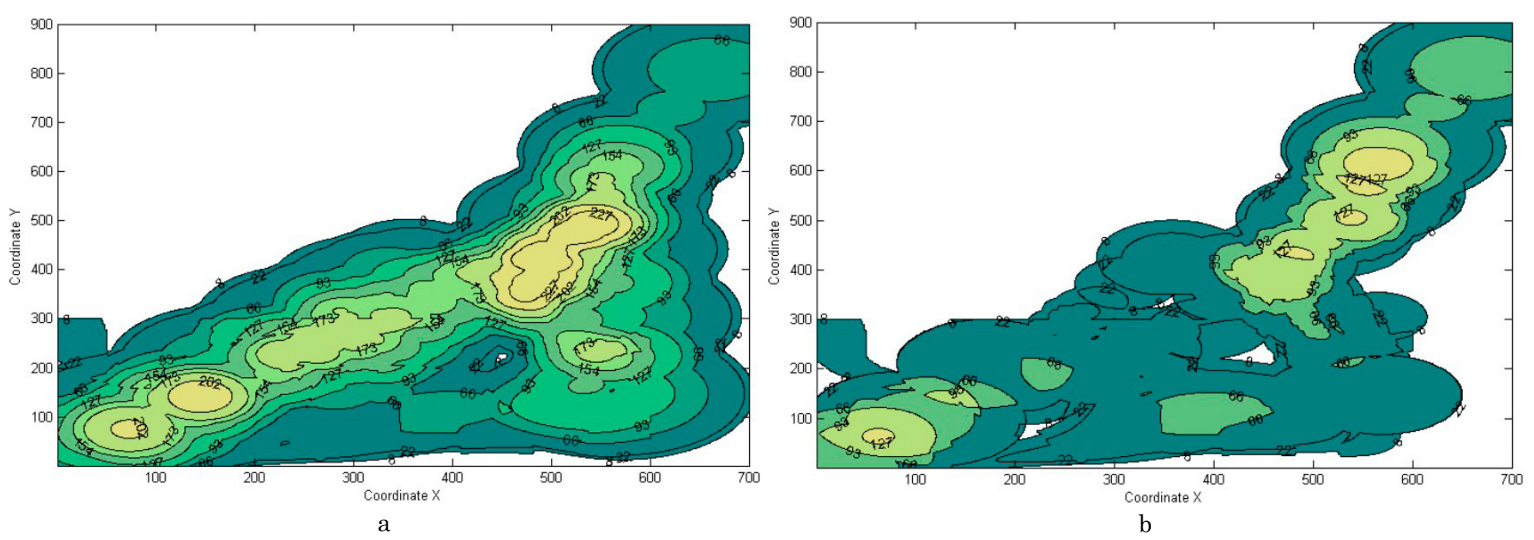

Fig. 7. Map of contamination of expanded territory by component 3 taking into account wind displacement before (a) and after optimization (b). Source: Authors.

Table 3. The extent of transboundary transfer of pollution plumes Components.

\begin{tabular}{|c|c|c|c|c|c|c|c|}
\hline \multirow{2}{*}{ Estimates } & \multicolumn{7}{|c|}{ Pollution components } \\
\cline { 2 - 9 } & 1 & 2 & 3 & 4 & 5 & 6 & 7 \\
\hline Ratio of intensities & 1.622 & 2.259 & 1.616 & 2.439 & 1.535 & 2.344 & 0.917 \\
\hline Covering of the initial area, \% & 98.7 & 91.8 & 61.8 & 49.6 & 67.6 & 49.6 & 28.6 \\
\hline Covering outer trail, \% & 235.9 & 205.8 & 82.0 & 106.7 & 91.2 & 100.2 & 27.0 \\
\hline
\end{tabular}

Source: Authors.

nounced northeastern direction and a maximum local elevation in [500 - 600, 350 - 500] the mentioned zone, this optimization directs the limitation of emission sources, which gave place to a new polluted chart with the whole relevant standards given (Fig 7b). It can be regard that the pollution load of the area [600 x 300] has decreased significantly as well the trail of power has done, although it prevails over the original ground likewise isolated charts related to other components of pollution were received as a regulation, hereafter transboundary pollution should be rejected due to these worldwide environmental issues should raise a political scope .

Researchers of this work have assessed the extent of cross-border transfer into a numerical experiment by comparing the total emissions for the entire components of pollution which are given in Table 3, the covered area is categorized by percentages consequently to the original magnitude [600 $x$ 300]. According to wind forecast, the magnitude of the boundary trail is significant and comparable for components 3-6, despite the fact that it does not have relevance for Fig. 7, being superior than the mentioned dimensions from the original ground sketched in Fig. 2.

According to the intensity, the prevailing trails are constructed by components number 2,4 and 6 , as well the minor element illustrated in fig. 7 the basic features assess significantly several complements to the graphical representation of the results related to enhancements
Modeling of wind displacement allows controlling in detail the balance of transboundary transfer of pollutants, which defines the strengthening or weakening of the polluting load of the area. The present work pursues to illustrate a complete set of rebuilt charts which fulfill the standards (regulate) of pollution from the controlled ground under the influence (wind displacement) of a group of sources of industrial emissions.

\section{Optimizing of pollution on $3 D$ areas for groups of emission sources and purification device groups}

$2 \mathrm{D}$ formulation of SIP problems (1) suggests that the environment surrounding emission points have a suitable level of unpolluted to the whole components of emission through which the mentioned components reach the external area, in this stage the accuracy is addressed to a considerable among of dust particles divided by fractions, in the same way these do not accomplish the Nano fractions, drip especially the gas particles, which should remain and pollute the environment itself. With reference to the $3 \mathrm{D}$ case $r$ in (10) it explains the radius of the sphere, on the surface as the dispersion present similar values .

$r=\sqrt{ }(t N(1, j)-X)^{2}+(t N(2, j)-Y)^{2}+(t N(3, j)-Z)^{2}$

where: $t N$ is the coordinate matrix of $R S$ sources placement. 
By enhancing the 3D scatter of pollution a numerical solution of the issue was accomplished through a set of sources and the improvement (capture) of pollution using appropriate gadgets then the 3D region was divided into subdomains $\mathrm{w}(\mathrm{s})$ in which different pollution standards have a significant role, on the other hand the creation of $3 \mathrm{D}$ subdomains using flexible spatial boundaries have shown difficulties; beside of this several sets of pollutant capture devices, long-lasting emission sources and group of emission were placed.

The configuration of the emissions (capture) included K components that build uneven sets for heterogeneous sources as devices mainly when the pollution components had different ranges of spread, now the scheme of summation of pollution by components for each point of the region was implemented since it was possible to set a track pollution area for each component of emissions under these circumstances surce $j$ is considered active in terms of $\mathrm{s}$ point, if $r(j, s)<R\left(r=(H(j) / a(k))^{1 / 2}\right.$ is identified as a limiting radius from $\mathrm{k}$ pollution component spread by $\mathrm{j}$ source) as the activity of source $j$ also depends on the presence of this component in the emission set as well the activity conditions are associated to “'AND' logic.

What is more, the main variables of the pattern and their parameters (size, powers, position, sets of components, variation coefficients) are considered adaptable emission of sources ( $\mathrm{RS}, \mathrm{H}, \mathrm{tN}$, kod1, a1); adaptable emission of sources (NRS, NH, tNN, kod2, a2); fencing devices (E, F, tE, kod3, a3).

For several $\mathrm{s}$ point in the area compliance with constraints (11) is declared:

$$
\begin{aligned}
& g(s)=\sum_{j=1}^{R S} \sum_{k=1}^{K} k o d 1(k, j)\left(-a 1(k) r(s, j)^{2}+(1-x(j) H(j))\right) \\
& +\sum_{j=1}^{N R S} \sum_{k=1}^{K} k o d 2(k, j)\left(-a 2(k) r(s, j)^{2}+N H(j)\right) \\
& -\sum_{j=1}^{E} \sum_{k=1}^{K} k o d 3(k, j)\left(-a 3(k) r(s, j)^{2}+F(j)-\operatorname{Norm}(w(s))\right) \leq 0
\end{aligned}
$$

Table 4. Reformable Sources.

\begin{tabular}{|c|c|c|c|c|c|c|c|c|c|c|c|}
\hline \multirow{2}{*}{ Param. } & \multicolumn{10}{|c|}{ Sources } \\
\cline { 2 - 14 } & 1 & 2 & 3 & 4 & 5 & 6 & 7 & 8 & 9 & 10 & 11 \\
\hline $\mathrm{H}$ & 426 & 362 & 51 & 365 & 253 & 951 & 587 & 619 & 411 & 286 & 423 \\
\hline \multirow{3}{*}{$\mathrm{tN}$} & 776 & 388 & 114 & 733 & 768 & 29 & 547 & 606 & 314 & 137 & 25 \\
\cline { 2 - 13 } & 383 & 320 & 169 & 317 & 262 & 340 & 87 & 297 & 262 & 282 & 111 \\
\cline { 2 - 13 } & 145 & 172 & 83 & 227 & 112 & 193 & 90 & 39 & 206 & 18 & 7 \\
\hline $\mathrm{x}$ & 1.00 & 0.88 & 0 & 0.48 & 0.44 & 1.00 & 0.75 & 0.43 & 0 & 0.34 & 0.12 \\
\hline$(1-\mathrm{x}) \mathrm{H}$ & 0 & 43 & 51 & 190 & 142 & 0 & 147 & 353 & 411 & 189 & 372 \\
\hline
\end{tabular}

Source: Authors. 
TABle 5. UnReformable SOURCES AND CLEANING DEVICES.

\begin{tabular}{|c|c|c|c|c|c|c|c|c|c|c|c|c|}
\hline \multirow{2}{*}{ Param. } & \multicolumn{3}{|c|}{ Sources } & \multirow{2}{*}{ Param. } & \multicolumn{8}{|c|}{ Devices } \\
\hline & 1 & 2 & 3 & & 1 & 2 & 3 & 4 & 5 & 6 & 7 & 8 \\
\hline $\mathrm{NH}$ & 216 & 98 & 194 & $\mathrm{~F}$ & 552 & 268 & 576 & 486 & 222 & 666 & 624 & 308 \\
\hline \multirow{3}{*}{$\mathrm{tNN}$} & 193 & 704 & 500 & \multirow{3}{*}{$\mathrm{tE}$} & 45 & 636 & 291 & 517 & 604 & 544 & 130 & 399 \\
\hline & 62 & 241 & 349 & & 199 & 75 & 178 & 284 & 110 & 262 & 48 & 384 \\
\hline & 137 & 55 & 284 & & 61 & 285 & 168 & 233 & 94 & 179 & 144 & 13 \\
\hline
\end{tabular}

Source: Authors.

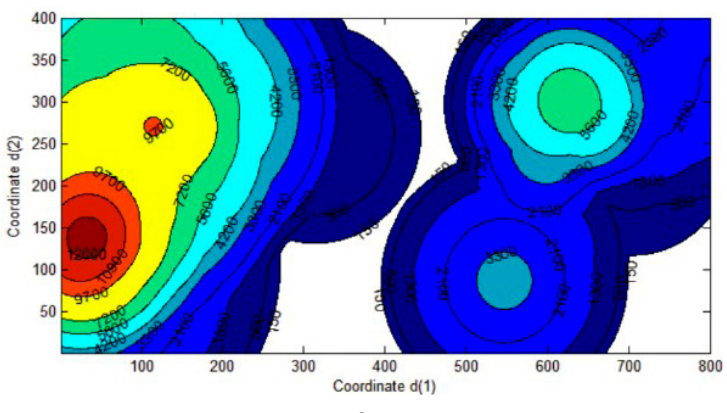

a

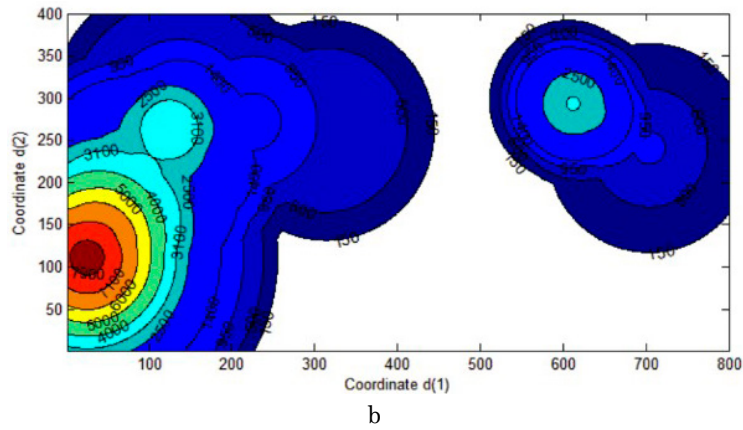

Fig. 8. Initial (a) and optimal (b) maps of total pollution (d3=1). Source: Authors.

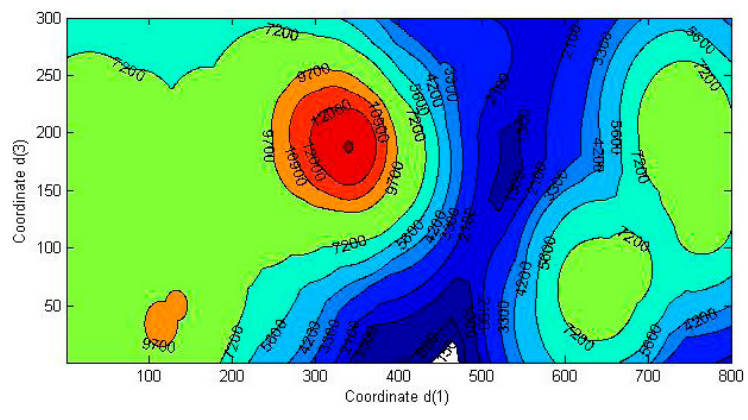

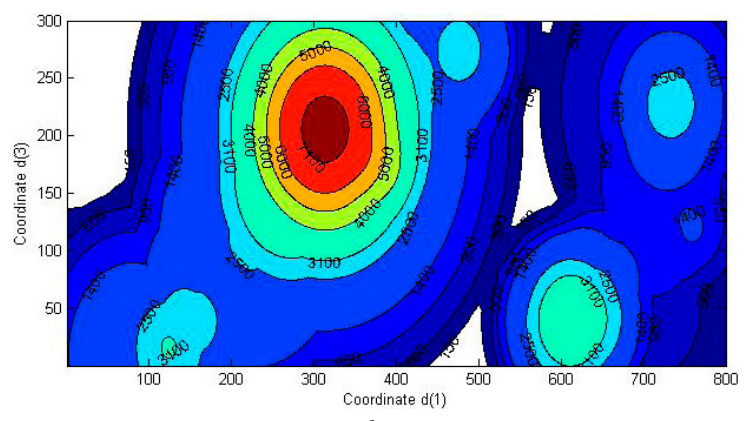

$\mathrm{b}$

Fig. 9. Initial (a) and optimal (b) maps of total pollution (d2=300). Source: Authors.

Pollution in the southwest area of the chart (Fig. 8 , a) is formed by emitter 11 (423) of average power, with 5 of the 7 active components, but the main point has to do with its location which is close to the level of the ground $(\mathrm{d}(3)=7)$. The support from emissions by source $3(51,4 / 7, \mathrm{~d}(3)=83)$ is not visible as well the low-positioned emission source $10(286,3 / 7,18)$, of average power and average activity, registers its presence in the west region by the local elevation. Source $6(951,3 / 7$, d (3) = 193), the maximum but inactive, does not evidence itself due to the displacement of emissions expressed in height.

Northeast of the area includes approximately 5 sources, but pollution distinguishes close to the half of the scope. Roles of sources $1(426,3 / 7, \mathrm{~d}(3)$ $=145), 4(253,4 / 7, \mathrm{~d}(3)=227), 5(253,2 / 7, \mathrm{~d}(3)=$ $112), 8(619,3 / 7, \mathrm{~d}(3)=39)$ can be seen only as a total; the lack of nearby cleaning devices should also be worthwhile. Device number $4(\mathrm{~d}(3)=233)$ and $6(\mathrm{~d}(3)=179)$ are strongly displaced upwards and their actions do not reach the ground, likewise the optimization consequences should be analyzed (Fig. 8b).

Fig. 9 shows the environmental pollution chart including elevations $(\mathrm{d}(3))$ in cross-section $\mathrm{d}(2)=300$ (a- initial, b- optimal). The initial chart points considerable pollution close to the entire cross-section of environment, and it determines the activity of emissions from several sources, both of them have been restructured $(6,10,9,2,8,4,1,5)$ and nonrestructured

$(3,2)$. Nevertheless, after suppressing in two stages all the initial elevations, the optimization has changed the chart significantly, the sources of power 6(1), 10(0.34), 2(0.88), 8(0.43), 4(0.48), 1(1), 5(0.44) have been significantly restructured. 
Thus, the applied algorithm produce specific parts of horizontal or vertical semi-sections 3D-environment $(\mathrm{d}[800,400,300])$ applicable for visual analysis.

\section{CONCLUSIONS}

Taking into account the results of this research work, it can be said that the problem of power from emitting pollution sources, by considering the area landscape and wind displacement of emissions, should be modeled like a semi-infinite programming problem, for these reason significant semi-infinite developments were performed in two dimensions [6], [8]. With regard to the third dimension it should be probable to handle it by using infinite constraints sets. The method, used for calculating the stopping criterion, does not consider the solution of additional difficulties these events differed from [1]-[3] which have been recently published and offer significant information about the use of three-dimensional patterns as well particular geographic features such as mountains [10], [11].

The obtained simulation results allowed the researchers to control specific points of ecological locations in order to carry out evaluations by zones and to employ the "wiring" of active sources by using environmental devices. On the whole, conclusions were making focused on strategies addressed to enhance the areas of source of emissions whose consequences are relevant for its environment, in addition average standards were consider as features which do not fulfill the process [12]-[14]; the improvement of semi-infinite offers a significant value which quick-impact assessments have enhanced its reliability on decisions, so that these should be appropriate for that purpose. Numerical solutions become the basic component to calculate and analyze a number of derivative criteria.

\section{Acknowledgements}

Researh Article supported by Universidad Nacional de Colombia. Proyect: "Minimización de los costos de control de contaminación del aire" Proyect Code: 11460. Proyect Starting Date: 2017-06-01. Proyect End Date: 2017-09-06.

\section{REFERENCES}

[1] V. V. Fedosov and A. Fedossova, "Semi-infinite model limits emissions of enterprises in áreas with a mix landscapes" Jour. of Comp. \& Inform. Tecnolog., vol. 86, no. 8, pp. 14-22, 2011.

[2] V. V. Fedosov and A. Fedossova, "Simulation control and limit industrial emissions in the presence of winds displacement", Jour. of Comp. \& Inform. Tecnolog., vol. 87, no. 9, pp. 29-35, 2011.

[3] V. V. Fedosov and A. Fedossova, "Numerical optimization of pollution in 3D área by groups of sources", Nanoengineering, vol. 7, no. 37, pp. 43-48, 2014.

[4] M. Lopez and G. Still, "Semi-infinite programming," Eur. J. Oper. Res., vol. 180, pp. 491-518, 2007. https://doi. org/10.1016/j.ejor.2006.08.045
[5] S. K. Zavriev, N.N. Novikova, and A.V., Fedossova, "Stochastic algorithm for solution of convex semi-infinite programming problem with equality and inequality constraints," Vestnik Mosc. Univer., ser. 15, no. 4, pp. 30$35,2000$.

[6] I. Vaz and E. C. Ferreira, "Air pollution control with semiinfinite program," Appl. Mathem. Model., vol. 33, pp. 1957 1969, 2009. https://doi.org/10.1016/j.apm.2008.05.008

[7] A. Fuduli, M. Gaudioso, G. Giallombardo, and G. Miglionico, "A partially inexact bundle method for convex semi-infinite minmax problems," Commun. in Nonlin. Sc. and Numer. Simulation, vol. 21, no. 1, pp. 172-180, 2015. https://doi. org/10.1016/j.cnsns.2014.07.033

[8] A. V. Fedossova, V.V. Kafarov, and D.P. Mahecha Bohórquez, "Solución Numérica del Problema de Control de Contaminación del Aire," Colom. J. Comp., no. 4, pp. 21-28, 2003.

[9] Y. V. Volkov and S.K. Zavriev, "A general stochastic outer approximations method," SIAM J. Control Optim., vol. 35, pp. 1387-1421, 1997. https://doi.org/10.1137/ S0363012994263202

[10] A. Gómez Gómez, "Minimización de costos del control de contaminación del aire en un espacio tridimensional”, M.S. thesis, Math. Dept., Univ. Nac. De Colombia, Bogotá, Colombia, 2013.

[11] A Gomez, A Fedossova, R. A. Britto, "A numerical solution for the air pollution control problem in 3D", DYNA, vol. 84 , no. 200, pp. 342-350, 2017. https://doi.org/10.15446/ dyna.v84n200.53883

[12] F. Fang, T. Zhang, D. Pavlidis, C.C. Pain, A.G. Buchan, and I.M. Navon, "Reduced order modelling of an unstructured mesh air pollution model and application in 2D/3D urban street canyons," Atmosph. Environ., vol. 96, pp. 96-106, 2014. https://doi.org/10.1016/j.atmosenv.2014.07.021

[13] M. Fallah Shorshani, M. André, C. Bonhomme, and C. Seigneur, "Modelling chain for the effect of road traffic on air and water quality: Techniques, current status and future prospects," Environ. Modelling \& Software, vol. 64, pp. 102-123, 2015. https://doi.org/10.1016/j.envsoft.2014.11.020

[14] V. V. Fedosov, A. Fedossova, "Optimización de emisiones de la red de carreteras de infraestructura urbana", Ing. Ind., vol.38, no. 2, pp. 143-153, 2017.

Alina Fedossova. Ph.D. in applied mathematics Moscow State University Lomonosov. Assistant Professor in the Universidad Nacional de Colombia, Bogotá. Her research interests include optimization and numerical methods. ORCID: https://orcid.org/00000003-4944-633X

Valery Fedosov. Free Research, Moscow, Russia. Ph.D. in Technology MGTU Bauman. Her research Interests include: Process flows of particles when applying protective coatings, Evacuation dust emissions of pollution sources in industrial ecology and Numerical implementation of semi-infinite optimization algorithms. ORCID: https://orcid.org/0000-00016586-6145

Oscar Yecid Buitrago Suescún. Chemical Engineer from the Universidad Nacional de Colombia, MSc in Industrial Engineering from Universidad De Los Andes and PhD student in Engineering at the Universidad de Carabobo. Assistant Professor in the School of Engineering of the Universidad Militar Nueva Granada, Colombia. His research interests includes optimization and materials. ORCID: https:// orcid.org/0000-0002-5064-3624 